\title{
A few seconds to screen for sarcopenia
}

Hong Kong Med J 2016;22:294

DOI: $10.12809 / \mathrm{hkmj} 164866$

To the Editor-I thank Ho et $\mathrm{al}^{1}$ for their very interesting article "Prevalence of pre-sarcopenia and sarcopenia in Hong Kong Chinese geriatric patients with hip fracture and its correlation with different factors" in the February 2016 issue of the Hong Kong Medical Journal. I would like to mention another recent sarcopenia study in elderly Chinese men and women with a mean age of 81 years. The research group led by Hong et $\mathrm{al}^{2}$ showed that $42 \%$ of female patients and $84 \%$ of male patients with hip fracture were sarcopenic. In this study, the prevalence of sarcopenia with vertebral fracture was $34 \%$ in women and $40 \%$ in men. I agree with the authors that screening measures should be implemented more. ${ }^{1}$ In a general practice setting, measurement of SARC-F sarcopenia scale is feasible, simple, quick and inexpensive, and does not expose the patient to any particular strain (Table). ${ }^{3}$ The scale has also been evaluated in elderly patients in Hong Kong with direct measurement of muscle mass, strength, and physical performance., ${ }^{4,5}$ If a SARC-F score of $\geq 4$ has been measured in an older patient, diagnosis of sarcopenia can be substantiated rather quickly. ${ }^{3}$ In my opinion, the SARC-F screen for sarcopenia should be routinely carried out among the Chinese elderly population every time they consult their doctor

Martin Hofmeister *, PhD

Consumer Centre of the German Federal State of Bavaria

Department Food and Nutrition

Mozartstraße 9, D-80336 Munich

Germany

*Corresponding author: hofmeister@vzbayern.de

\section{References}

1. Ho AW, Lee MM, Chan EW, et al. Prevalence of presarcopenia and sarcopenia in Hong Kong Chinese geriatric patients with hip fracture and its correlation with different factors. Hong Kong Med J 2016;22:23-9.

2. Hong W, Cheng Q, Zhu X, et al. Prevalence of sarcopenia and its relationship with sites of fragility fractures in elderly Chinese men and women. PLoS One 2015;10:e138102.

3. Malmstrom TK, Morley JE. SARC-F: a simple questionnaire to rapidly diagnose sarcopenia. J Am Med Dir Assoc 2013;14:531-2.

4. Woo J, Leung J, Morley JE. Validating the SARC-F: a suitable community screening tool for sarcopenia? J Am Med Dir Assoc 2014;15:630-4.

5. Woo J, Leung J, Morley JE. Defining sarcopenia in terms of incident adverse outcomes. J Am Med Dir Assoc 2015;16:247-52

TABLE. The Simple "SARC-F" Sarcopenia Questionnaire (0-10 points)

\begin{tabular}{lll}
\hline Component & Question & Scoring \\
\hline Strength & How much difficulty do you have in lifting and carrying 10 pounds? & $\begin{array}{l}\text { None }=0 \\
\text { Some }=1\end{array}$ \\
& & A lot or unable $=2$
\end{tabular}

